\title{
INFLUENCE OF CONTROLLED FIELD TRAFFIC ON SOIL QUALITY INDICATORS
}

\author{
Dumitru Gutu, Josef Hula, Petr Novak, Stanislav Kovar \\ Czech University of Life Sciences Prague, Czech Republic \\ novakpetr@tf.czu.cz
}

\begin{abstract}
A semi-operational field trial that focused on Controlled Traffic Farming (CTF) was established in a ten hectare field. The experiment was established in Krrinec in the Central Bohemia Region. The content of particles smaller than $0.01 \mathrm{~mm}-38.3 \%$, soil type: loamy soil, the content $\mathrm{C}_{\mathrm{t}} 3.12 \%$. The working width module was 6 meters. The experiment was conceived as a multiannual. The results of the experiment confirmed the benefit of concentration of machinery passes into permanent traffic lines in order to prevent adverse technogenic soil compaction. Apart from the beneficial effect on the soil physical characteristics and water infiltration capabilities, the concentration of passes into permanent traffic lines inflicted better work quality of soil tillage and sowing implements. Clod size and structure distribution, evenness of soil surface, degree of plant residue cover, distribution and incorporation of plant residues into soil profile can be ranked among the evaluation parameters of soil tillage quality. Within the evaluation of plant residue incorporation quality, the highest degree of plant residue incorporation into the soil profile was measured for the variant with zero passes (Variant 3), where almost $70 \%$ of plant residues were incorporated. Within the variants with machinery passes present, the measured values were substantially lower, i.e. $26 \%$ for Variant 1 and $17 \%$ for Variant 2.
\end{abstract}

Keywords: CTF, soil properties, tracks.

\section{Introduction}

Current intensive farming systems in agriculture are unfortunately connected with negative impacts on soil when standard production and non-production functions of soils are disturbed. Soil compaction is one result of these impacts. E.g., Kingwell et al. [1] stated that undesirable so called technogenic compaction poses one of the main problems for modern agriculture. This undesirable compaction is most frequently connected with the wheel traffic of heavy-duty farm machines. Soil compaction has a negative impact mainly on physical properties of soil, both in the short or long run, which is manifested in an increase in penetrometer resistance and bulk density of soil, in worsened indicators of soil tillage quality. It results in a decrease in soil porosity and minimum air capacity, worsening of hydraulic properties of soil and soil aggregate stability [2;3]. All these parameters are closely related with crop yields, as they influence them jointly [4].

Currently, agricultural businesses are looking for methods how to reach the lowest possible costs per unit production. It is also useful to consider whether the used cultivation technologies do not deteriorate soil properties by excessive soil compaction so that it implies a subsequent increase in the costs of some operations [5]. Conditions for soil tillage and initiation of crop stands are significantly influenced by the previous wheel traffic of farm machines, transportation vehicles and combines. Besides farm equipment weight and mean contact pressures the degree of soil compaction is significantly affected by instantaneous soil resistance to [6]. Compaction of subsoil layers caused by excessive load on the soil is often irreversible [7], or it is hardly reparable [8]. The objective was to evaluate the effect of the wheel traffic of farm equipment on the soil on some indicators of the quality of subsequent soil tillage in the technology of permanent wheel tracks.

\section{Materials and methods}

Parameters of soil tillage were measured in the Křinec locality in the Central Bohemian Region. Measurements were done on a plot of 10 ha in size. Soil conditions: loamy soil - content of particles smaller than $0.01 \mathrm{~mm}-38.3 \%$, Ct (combustible carbon) content $3.8 \%$. The evaluated parameters were soil cloddiness, crop residue coverage of the soil surface, extent of crop residue incorporation into soil and penetrometer resistance of soil. In the autumn of a previous year after winter wheat harvest the plot was tilled with a Farmet Hurikan 6000 tine cultivator to a depth of $0.08 \mathrm{~m}$. Soil tillage with a Horsch Tiger 4MT cultivator to a depth of $0.25 \mathrm{~m}$ followed. There were no passes on the plot until spring, when subsequent operations were organized in a controlled traffic farming (CTF) system with the module of 6-m working width of the implements, with the organization of passes in an OutTrac system (Fig. 1). For the application of chemicals for plant protection and for fertilization with mineral fertilizers traffic lanes were used, the working width of a sprayer and fertilizer spreader was 
$18 \mathrm{~m}$. The traffic lane width was $0.50 \mathrm{~m}$. On the plot there are three areas with different levels of traffic: no-traffic soil, soil with less intensive traffic and soil with intensive traffic. The total width of wheel tracks is influenced by different spans of the tractor and combine wheels. To evaluate the influence of the types of wheels on the soil in a controlled traffic farming system three treatments of wheel tracks were chosen, Fig. 1.

Treatment 1 - Tractor wheel tracks during sowing, application of chemicals for plant protection, application of mineral fertilizers and soil tillage,

Treatment 2 - Tractor wheel tracks during sowing and soil tillage, wheel tracks of a combine,

Treatment 3 - Out of wheel tracks.

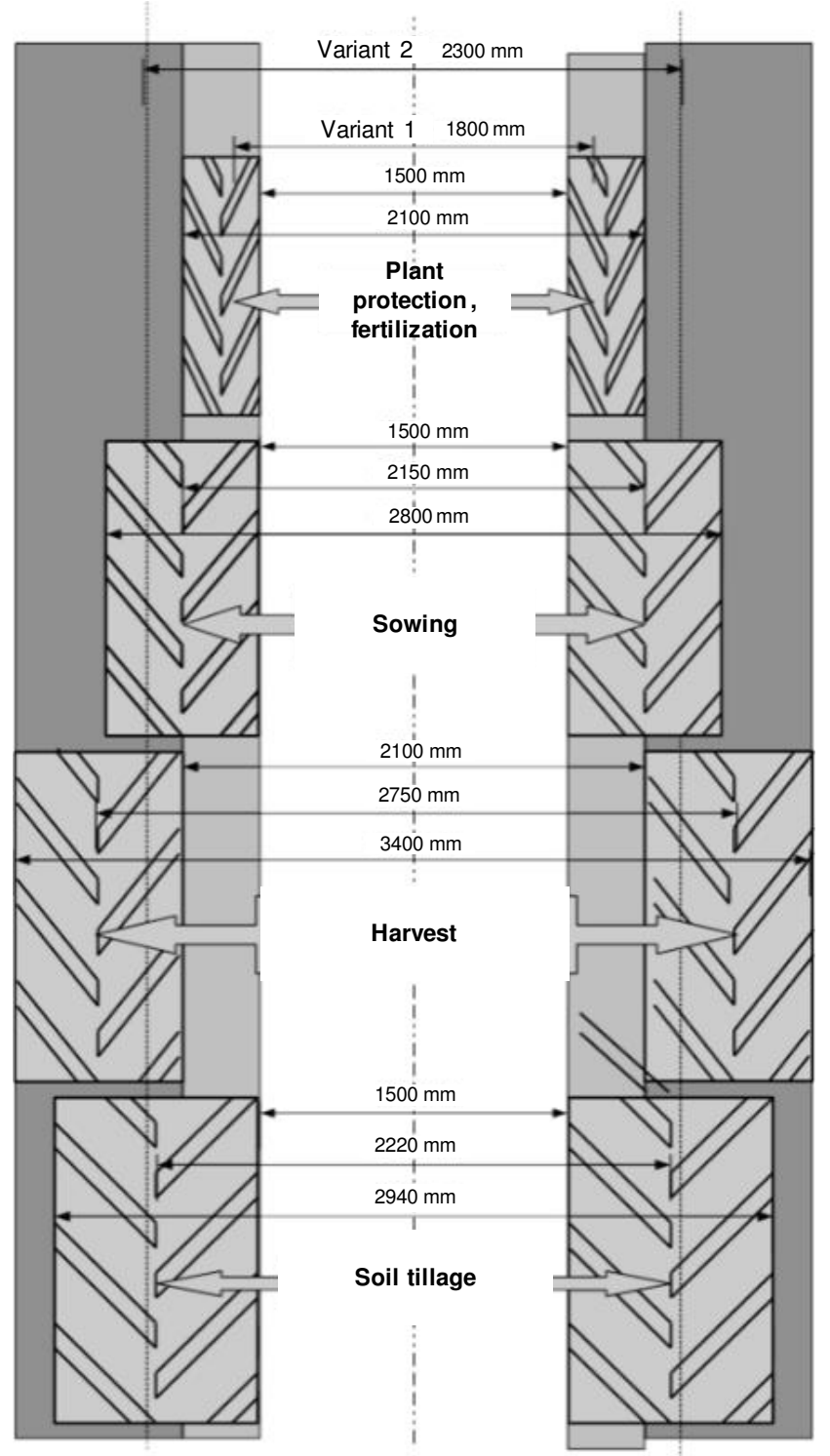

Fig. 1. Wheel ruts of machines after their concentration to permanent traffic lanes

The extent of crop residue incorporation and percentage of unincorporated crop residues can be expressed on the basis of crop residue weight determination. The extent of crop residue incorporation is determined by taking crop residues from an area of $0.25 \mathrm{~m}^{2}$ before soil tillage and this amount is weighed (4 replications). Subsequently, the amount of unincorporated crop resides after soil tillage is taken and weighed. The percentage of crop residues incorporated into soil and unincorporated is expressed. Rate of incorporation of plant residues and the percentage of unincorporated residues are determined according to the relationships defined by Vávra et al. [9].

The crop residue cover of the soil surface was evaluated by the digital image analysis. A digital image is reduced to primary colours, where the boundary of the colours between crop residues and soil 
is exactly defined. Consequently, the percentage representation of colours in the image is computed, and the percentage cover of the soil surface with crop residues is determined.

Cone index was measured in ten replications from each studied treatment to a depth of $0.40 \mathrm{~m}$. Samples to determine the weight percentage of clods were taken from individual treatments from a part of the soil profile $0.25 \mathrm{~m}^{2}$ in size to a depth of actual soil tillage. Classification of the sizes of particle diameters: below $10 \mathrm{~mm}, 10-30 \mathrm{~mm}, 30-50 \mathrm{~mm}, 50-100 \mathrm{~mm}$ and above $100 \mathrm{~mm}$ (4 repeats).

Data were processed using the programmes MS Excel (Microsoft Corp., USA) and Statistica 12 (Statsoft Inc., USA).

The input hypothesis of measurement is the negative effect of tracks on the soil properties (especially physical).

\section{Results and discussion}

Fig. 2 illustrates the penetrometer resistance of soil on $19^{\text {th }}$ August. On that date there was a significantly larger difference in the resistance values between treatments 1,2 and treatment 3 . Obviously, the values in treatment 2 (cropped wheel tracks) increased as a result of combine passes. Treatment 3 (out of the wheel tracks) had the lowest penetrometer resistance and at the same time the smallest range of values in the entire measured profile, to a depth of $0.40 \mathrm{~m}$. It means that the soil at places without wheel traffic has lower heterogeneity than at places after implement passes. This also confirms the measurement of the total porosity of the soil at the same term (see Table 1).

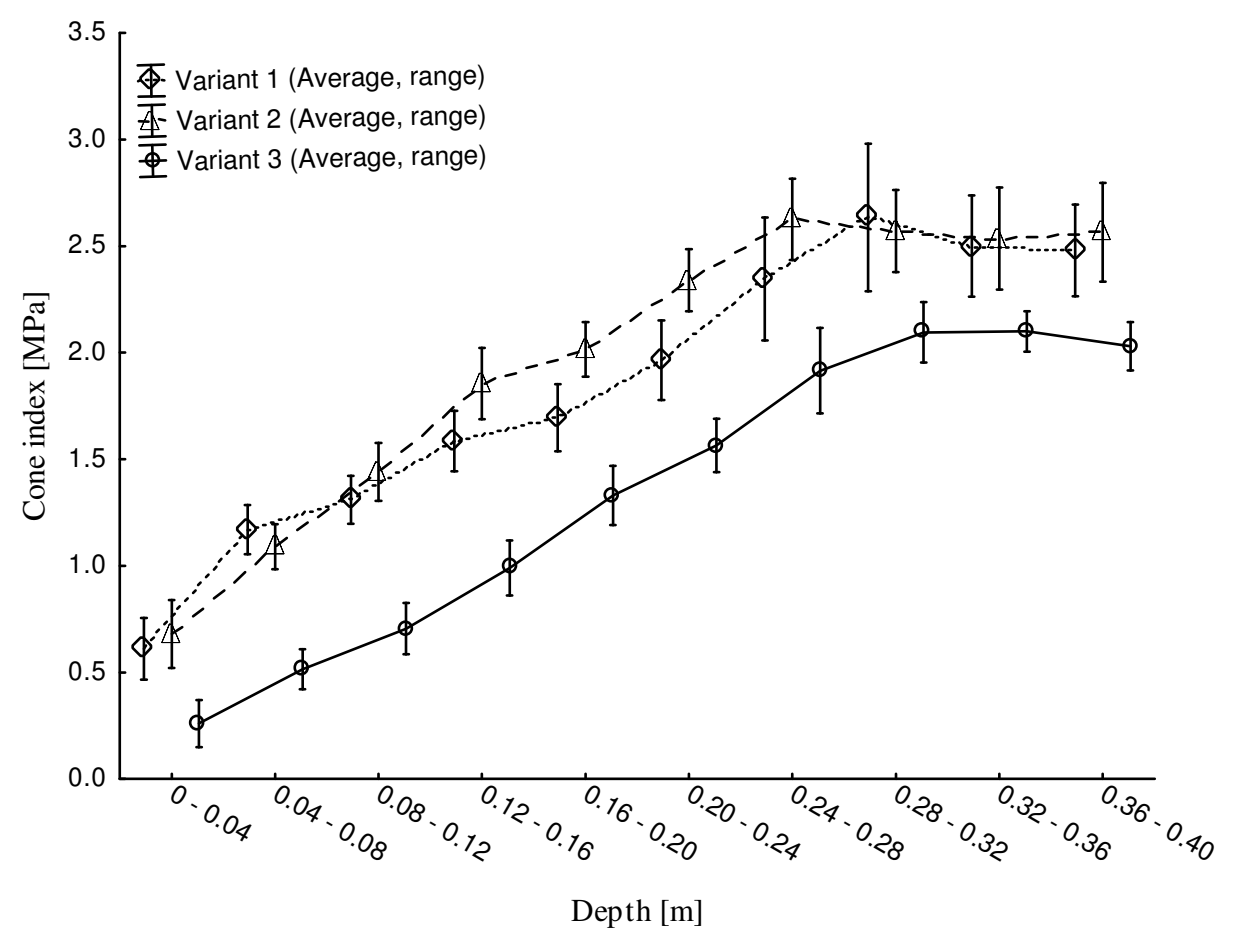

Fig. 2. Peneration resistance of soil

Table 1

Soil moisture and soil porosity 19 August

\begin{tabular}{|c|c|c|c|c|c|c|}
\hline \multicolumn{4}{|c|}{ Soil moisture, \% Vol. } & \multicolumn{3}{c|}{ Soil porosity, \% } \\
\hline Depth, m & Variant 1 & Variant 2 & Variant 3 & Variant 1 & Variant 2 & Variant 3 \\
\hline $0-0.01$ & 31.1 & 34.1 & 33.6 & 38.7 & 41.7 & 51.8 \\
\hline $0.01-0.02$ & 30.3 & 32.5 & 31.2 & 38.7 & 40.6 & 41.9 \\
\hline $0.02-0.03$ & 28.8 & 30.3 & 30.7 & 38.1 & 37.7 & 39.6 \\
\hline $0.03-0.04$ & 30.4 & 30.4 & 28.8 & 40.7 & 39.9 & 41.1 \\
\hline
\end{tabular}

Rate of incorporation of plant residues into the soil was evaluated at the same time. In the regime of permanent wheel tracks on the plot the incorporation of crop residues was evaluated during soil 
tillage - stubble-breaking on 19 August. Stubble-breaking followed after common pea harvest. A Horsch Joker 6 RT disk harrow with the working width of $6 \mathrm{~m}$ was used for soil tillage. The soil tillage depth was set at $0.8 \mathrm{~m}$. Three replications were done in each treatment. The values of crop residue incorporation into soil are represented in Fig. 3. There were found statistically significant differences between the variant with zero number of passes (variant 3 ) and other variants.

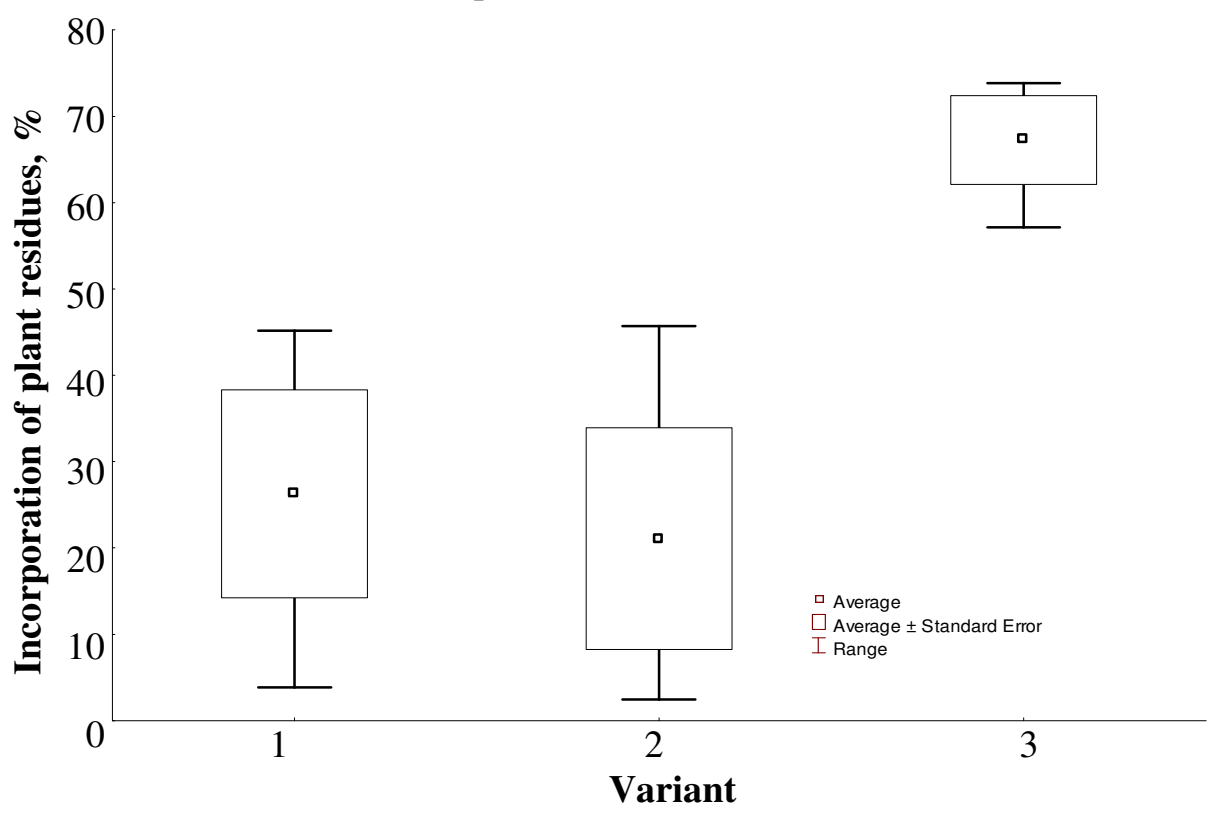

Fig. 3. Box plot graph of incorporation of plant residues after stubble

Evaluation of the percentage of crop residue incorporation showed that the highest percentage of crop residue incorporation was observed in the treatment with the zero number of passes (treatment 3 ). Almost $70 \%$ of all crop residues were incorporated in this treatment. In treatments with wheel traffic on the soil the percent incorporation was distinctly lower, $26 \%$ in treatment 1 and $17 \%$ in treatment 2. The percentage of residue incorporation is related to the weight of crop residues taken randomly on the plot before stubble-breaking. The results document that wheel traffic influenced the quality of crop residue incorporation into soil in this case.

Another indicator of soil tillage quality is the cover of the soil surface with plant biomass that was determined after the incorporation of emerged plants from shed pea seeds using the digital image analysis. The liquidation and incorporation of emerged plants into soil were done with a Farmet Hurikan 600 tine cultivator to a depth of $150 \mathrm{~mm}$. The results of this analysis are shown in Fig. 4. In this case there is a great range of measured values in treatment 2 . The position of particular boxes in the graph shows that in the measurement of the soil surface cover after the liquidation and incorporation of emerged plants no significant statistical differences were found between the values of particular treatments. This fact can be ascribed to the uneven stand of emerged plants from shed pea seeds on the soil surface. The graph also shows the highest cover of the soil surface in the treatment with the zero number of passes (treatment 3 ) of all the evaluated treatments, the cover of the soil surface was $14-18 \%$ in treatment 3 .

Fig. 5 illustrates the percentage of aggregate size fractions in individual treatments of wheel traffic. The percentage of soil aggregate weights was determined immediately after soil tillage on 15 September. Agronomic requirements for the quality of seedbed preparation indicate that there should be no clods larger than $50 \mathrm{~mm}$ in diameter in the seedbed layer and in the surface layer of soil. Fig. 5 documents that this requirement for the clod size was met only in treatment 3 , in the treatment without the effect of passes on the soil. Taking into account the percentage of aggregate size fractions in the particular treatments of wheel traffic on the soil, it is evident that the passes on the soil influenced mainly the formation of larger soil aggregates. Especially the treatment with no passes had the lowest proportion of the largest particles and, on the contrary, the highest proportion of particles below $10 \mathrm{~mm}$. 


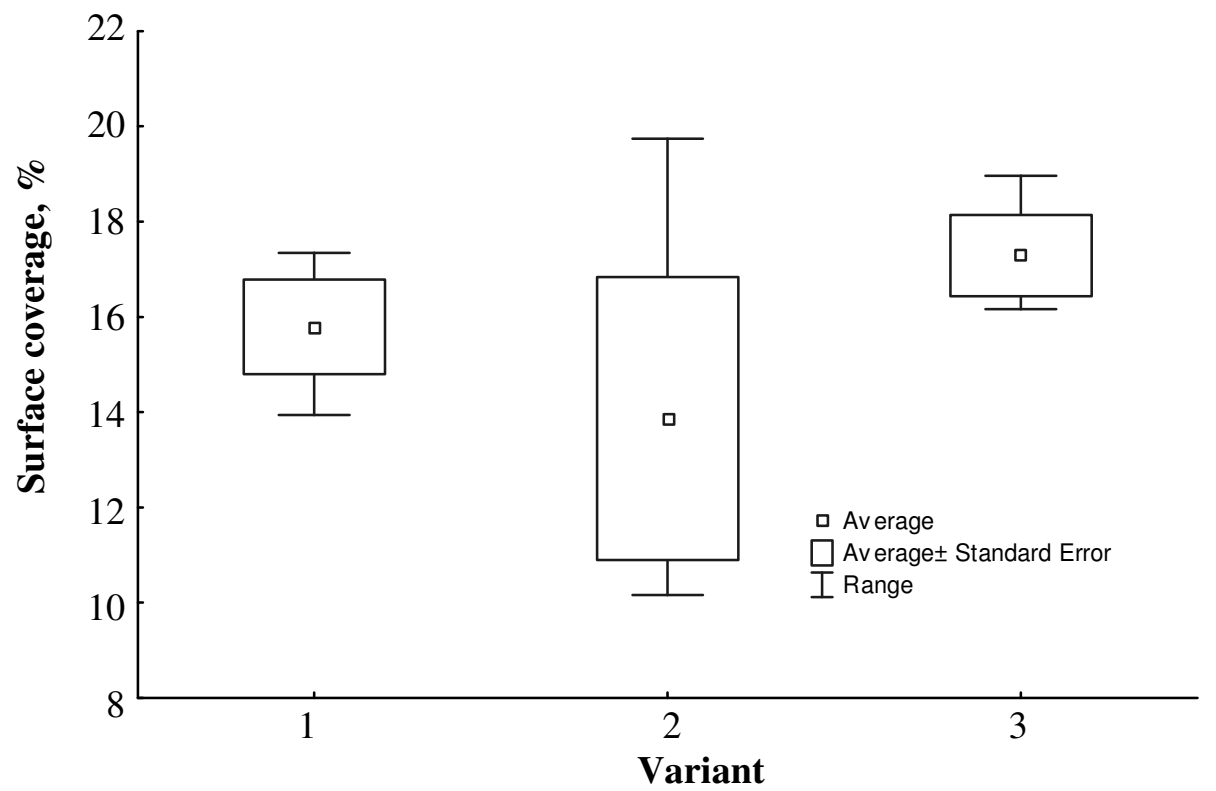

Fig. 4. Box plot graph of soil surface coverage

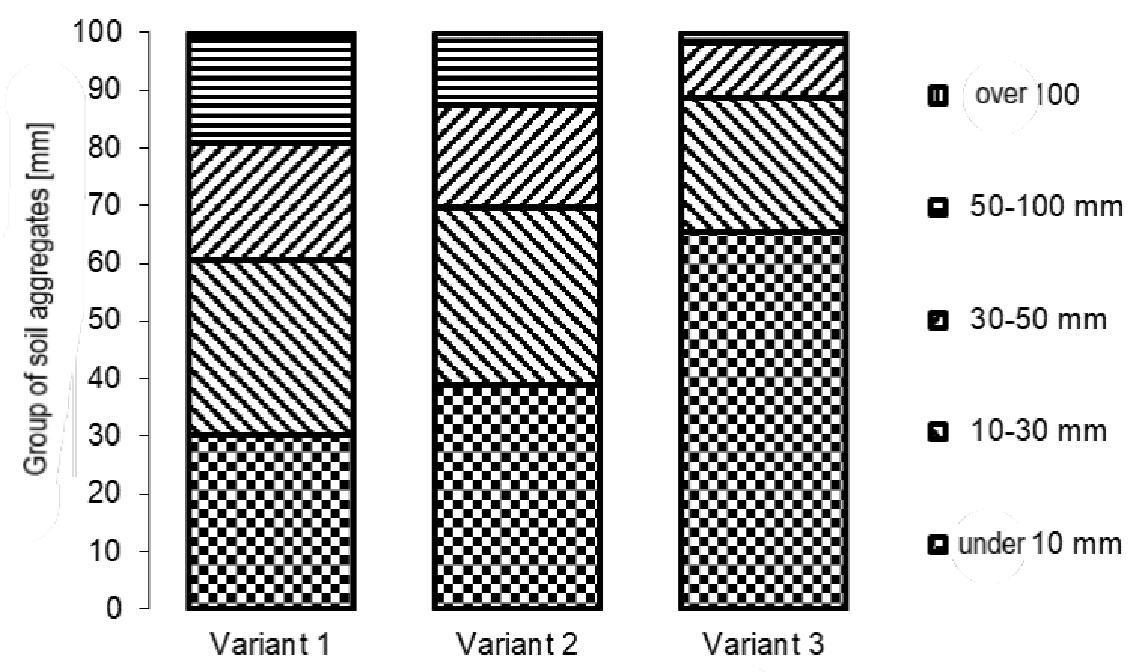

Fig. 5. Size fraction of soil aggregates at depths up to $150 \mathrm{~mm}$

Similar results were reported by Watts \& Dexter [10]. The results complement the findings of Chamen [5] about the contribution of CTF not only to a reduction in the extent and intensity of harmful soil compaction, but also to the required quality of soil tillage. It has been confirmed that if the farm has appropriate implements at disposal and if the CTF system is used on the farm, the soil tillage quality is not worsened due to the wheel traffic of tillage implements in the direction of all other tracks on the plots [11]. Kingwell \& Fuchsbichler [1] accentuated also the effect on other indicators of agricultural production. In addition, CTF is likely to cause reductions in environmental issues such as ammonia emissions, soil water runoff, nutrients and agrochemicals [12]. CTF has positive impacts on the restoration of impaired soil structure [13].

\section{Conclusions}

1. The results obtained by evaluation of the effect of wheel traffic of farm machines on the soil on some parameters of soil tillage quality in the technology of permanent wheel tracks confirm the first hypothesis.

2. Soil under wheel traffic has higher values of penetrometer resistance, on the soil with lower or zero number of passes the percentage of crop residue incorporation is higher and the soil aggregate sizes are improved. 
3. These factors can substantially influence the quality of stand initiation and have a direct effect on crop yield.

\section{Acknowledgements}

Supported by CULS Prague (Project No. IGA 31160/1312/3117).

\section{References}

[1] Kingwell R., Fuchsbichler A. The whole-farm benefits of controlled traffic farming: An Australian appraisal. Agricultural Systems, vol. 104 (7), 2011, pp. 513-521.

[2] Alakukku L. Persistence of soil compaction due to high axle load traffic. Soil and Tillage Research, vol. 37, 1996, pp. 211-238.

[3] Ahmad N., Hassan F., Belford, R. K. Effects of soil compaction in the sub-humid cropping environment in Pakistan on uptake of NPK and grain yield in wheat (Triticum aestivum). Field Crops Research, vol. 110, 2009, pp. 61-68.

[4] Håkansson I. Compaction of arable soils. Reports from the division of soil management. Uppsala: Swedish University of Agricultural Sciences, 2005, 155 p.

[5] Chamen T. The impact of tillage practices on the soil and wider environment, with particular regard to arable cropping in England. GeoEcology, vol. 32, 2000, pp. 370-383.

[6] Keller T., Arvidsson J. Technical solutions to reduce the risk of subsoil compaction: effects of dual wheels, tandem wheels and tyre inflation pressure on stress propagation in soil. Soil and Tillage Research, vol. 79, 2004, pp. 191-205.

[7] Horn R., Fleige H. A method for assessing the impact of load on mechanical stability and on physical properties of soils. Soil and Tillage Research, vol. 73, 2003, pp. 89-99.

[8] Berli M., Kirby J., Springman S., Schulin R. Modelling compaction of agricultural subsoils by tracked heavy construction machinery under various moisture conditions in Switzerland. Soil and Tillage Research, vol. 73, 2003, pp. 57-66.

[9] Vávra V. 2007. Mechanization of agriculture 2. České Budějovice: University of Southern Bohemia, 54-57 (in Czech).

[10] Watts C., Dexter A. Traffic and seasonal influences on the energy required for cultivation and on the subsequent tilth. Soil and Tillage Research, vol. 31, 1994, pp. 303-322.

[11] Kroulík M., Kumhála F., Hůla J., Honzík I. The evaluation of agricultural machines field trafficking intensity for different soil tillage technologies. Soil and Tillage Research, vol. 105, 2009, pp.171-175.

[12] Gasso V., Sørensen C. A., Oudshoorn F. W., Green O. Controlled traffic farming: A review of the environmental impacts. European Journal of Agronomy, vol. 48, 2013, pp. 66-73.

[13] McHugh A. D., Tullberg J. N., Freebairn D. M. Controlled traffic farming restores soil structure. Soil and Tillage Research, vol. 104(1), 2009, pp.164-172. 